\title{
Redução do tamanho do lote em projetos como estratégia de implementação do fluxo contínuo em sistemas pré-fabricados
}

\author{
Reduction of batch size in design as a strategy for the \\ implementation of continuous flow in pre-fabricated \\ systems
}

\section{lamara Rossi Bulhões \\ Flávio Augusto Picchi}

\section{Resumo}

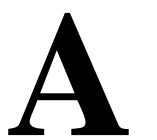

s obras de estruturas pré-fabricadas de concreto para fins comerciais e industriais normalmente são de grande porte e o processo de montagem das mesmas não apresenta grande complexidade, se analisado individualmente. Entretanto, quando se considera todo sistema de produção, este pode ser considerado de grande complexidade, em função das interdependências entre as etapas, da variabilidade que existe no processo de montagem, e também pelo fato de que a empresa necessita gerenciar múltiplos projetos simultaneamente. $O$ processo de projeto exerce grande influência nos processos posteriores e pode ser a origem de alguns problemas típicos deste tipo de obra, tais como: estoque das peças na obra, estoque em processo de peças (montadas), e atrasos na entrega das peças pela fábrica. Uma das possíveis estratégias para eliminar alguns destes problemas é a redução do tamanho de lote de projeto. O presente artigo tem como objetivo apresentar os resultados da implementação do fluxo contínuo em projeto a partir da redução do tamanho do lote de projetos de estruturas pré-fabricadas de concreto. A pesquisaação foi usada como estratégia de pesquisa no desenvolvimento do estudo, sendo realizados dois estudos empíricos em empreendimentos de uma mesma empresa. Os resultados indicaram que a redução do tamanho do lote de projetos contribuiu efetivamente para aumentar o grau de integração na gestão das etapas de projeto, fabricação e montagem.

Palavras-chave: Projeto. Fluxo continuo. Mapa de Fluxo de Valor. Redução do tamanho do lote.

lamara Rossi Bulhões Universidade Federal da Bahia Salvador - BA- Brasil

Flávio Augusto Picchi Lean Institute Brasil Universidade Estadual de Campinas São Paulo - SP - Brasil

Recebido em 06/07/13 Aceito em 20/09/13

\begin{abstract}
The production of pre-fabricated concrete structures for commercial and industrial buildings usually consist of large projects, and the assembly process has a low degree of complexity, if analyzed individually. However, when the whole production system is considered, those projects have a high degree of complexity, due to the large number of interdependences, the variability of the assembly process on site, and also the need of managing multiple projects simultaneously. The design process has much influence in downstream processes, and may cause some problems that are typical of this type of production system, such as: inventory of parts in the construction site waiting to be assembled, work-inprogress of partially assembled structures, and delays in the delivery of parts by the manufacturing plant. One of the possible ways of reducing work-in-progress and the lead-time of parts is the reduction of design batch size. This article presents the results of the implementation of the principle of continuous flow in design, based on the reduction of the batch size in the design of pre-fabricated concrete structures. Action-research was the research strategy adopted in this investigation, and two empirical studies were carried out in projects from the same company. The results indicate that the reduction of batch size has contributed to improve the integration of the three project stages (design, pre-fabrication, and assembly).

Keywords: Design. Continuous flow. Valu Stream Mapping. Reduction of batch size.
\end{abstract}




\section{Introdução}

Os sistemas de estruturas pré-fabricadas em concreto armado tem um importante papel no segmento de obras industriais e comerciais. Muitas destas obras tem a tipologia de galpões, cujo processo de montagem é relativamente simples, podendo ser realizado com grande velocidade.

Entretanto, ao se considerar o processo de produção destas estruturas de forma mais ampla, incluindo projeto, pré-fabricação e montagem de obra, o grau da complexidade aumenta. Considerando a definição de complexidade adotada por Williams (2002), este tipo de operação apresenta uma elevada complexidade estrutural, devido ao elevado grau de interdependência entre as atividades de projeto, fabricação e montagem, e também pelo fato de que a capacidade da empresa é utilizada para atender diversas obras simultaneamente. Estas obras também possuem um outro tipo de complexidade, decorrente do elevado grau de incerteza (WILLIAMS, 2002), que existe nos processos de montagem, por fatores inerentes às atividades realizadas em canteiro de obra, tais como efeitos das intempéries, e variabilidade nas atividades antecessoras.

Em função disto, muitos estoques são encontrados nos processos de produção e montagem de peças pré-fabricadas de concreto armado, incluindo estoques no pátio da fábrica, que não podem ser enviados para os canteiros de obra, e estoques de peças nas próprias obras, que não podem ser montadas por não existirem lotes completos (SACKS at al., 2003).

$\mathrm{O}$ processo de projeto, por ser o primeiro na sequência de produção, tem grande impacto nos processos posteriores. Em que pese a sua importância, o planejamento e controle de projetos é normalmente realizado de maneira informal, sem que haja um controle efetivo na sua realização. A literatura sobre planejamento e controle deste processo é relativamente escassa e as ferramentas tradicionais de gestão de empreendimentos tem sido apontadas como inadequadas, em função da natureza interativa e multi-disciplinar da atividade de projeto (AUSTIN et al., 1994; BALLARD, 2002). Por outro lado, a falta de eficácia do planejamento e controle de projetos tem sido apontada como a causa de diversos problemas nos empreendimentos de construção, tais como a falta de coordenação e comunicação entre diferentes disciplinas, alocação inadequada de recursos, falta de informação para completar as atividades de projeto, inconsistências nos documentos produzidos, re-trabalhos nas etapas finais de projeto, e atrasos na entrega de informações de projeto (AUSTIN et al. 1994; KOSKELA et al. 1997; TRESCASTRO, 2005).

No caso de projetos de estrutura pré-fabricadas, Ballard, Harper e Zabelle (2003) apontam como problemas típicos a existência de grandes lotes de informação, e a sub-otimização do processo através da priorização dos projetos das peças com maior repetição na obra. Os mesmos autores afirmam que, em consequência, as peças são préfabricadas e enviadas para obra nessa ordem, sendo esta uma das mais importantes causas de estoques em sistemas de estruturas pré-fabricadas.

O presente artigo discute a redução do tamanho do lote em projeto como uma estratégia para implementação de fluxo contínuo no sistema préfabricado de concreto $\mathrm{O}$ fluxo contínuo é um dos princípios básicos da Mentalidade Enxuta (WOMACK; JONES, 1996), definido como a produção de uma peça de cada vez (ou um lote pequeno de itens), com cada item sendo passado de um processo para o seguinte, sem interrupção entre estes (ROTHER; SHOOK, 1999). A busca pelo fluxo contínuo representa, de fato, um mecanismo indutor de melhoria de todo o sistema de produção. Liker (2004) apresenta alguns benefícios decorrentes da implementação do fluxo contínuo: melhoria da qualidade, criação de flexibilidade real, aumento da produtividade, identificação de pontos de ociosidade e sobrecarga de trabalho no sistema, liberação de espaço e redução do custo de estoques.

Segundo Reinertsen (1997), a redução do tamanho dos lotes de informação é um dos principais mecanismos para gerenciar o processo de projeto em situações de incerteza e interdependência entre as atividades. $\mathrm{O}$ mesmo autor afirma que, devido à natureza do processo de projeto, pode haver grande incerteza em relação à chegada das informações de entrada das atividades de projeto (por exemplo, requisitos dos clientes), assim como quanto à duração das mesmas, o que pode resultar na existência de filas de atividades no processo de projeto. No contexto da construção civil, o estudo de Trescastro (2005) apontou os benefícios na redução do tamanho do lote de projetos, em empreendimentos rápidos, complexos e com grande incerteza, nos quais as etapas de projeto e de produção em canteiros de obra necessitam ser sobrepostas.

Neste artigo são apresentados os resultados da implementação de melhorias no projeto de estruturas de pré-fabricadas de concreto, principalmente com relação à redução do tamanho do lote, a partir da adaptação de conceitos e 
ferramentas da Mentalidade Enxuta ao contexto da construção civil. Merece destaque a adaptação da ferramenta Mapeamento do Fluxo de Valor (MFV), que vem sendo amplamente aplicada na produção (por exemplo, Yu et al. (2009) e Dentz et al., (2009)), no diagnóstico e planejamento do processo de projeto.

Uma importante delimitação deste estudo é o fato de que a identificação dos problemas e a implementação de melhorias tiveram foco em projetos individuais. Portanto, não foram abordados problemas gerenciais decorrentes do ambiente de múltiplos projetos.

Este estudo está inserido dentro de uma pesquisa mais ampla, na qual se investigou a aplicação do princípio do fluxo contínuo na montagem das estruturas pré-fabricada de concreto, com base em estudos empíricos realizados em uma grande empresa deste setor no Brasil (BULHÕES, 2009). Nessa pesquisa foram evidenciados alguns problemas relacionados ao processo de projeto, tais como: estoque das peças na obra, estoque em processo de peças (montadas), e atrasos na entrega das peças pela fábrica.

\section{Projeto como fluxo}

No contexto da construção civil, o conceito de fluxo foi introduzido por Koskela (1992), para explicar os processos de produção, que eram tradicionalmente vistos apenas como uma sequência de atividades de transformação. O mesmo autor define processo produtivo como um fluxo de materiais ou informações, desde a matéria-prima até o produto final, sendo o mesmo constituído por atividades de transporte, estoque, processamento (ou conversão) e inspeção, sendo que apenas o processamento pode agregar valor ao produto. É importante salientar, entretanto, que o conceito de agregar valor está inerentemente vinculado à perspectiva do cliente que está sendo considerado - ou seja, uma determinada atividade pode não agregar valor para um cliente final, mas agrega valor para um cliente interno (Koskela, 1992).

O processo de projeto pode ser entendido com base na mesma conceitualização, sendo as atividades de conversão aquelas geradoras de novas informações, e as atividades de troca de informações, retrabalho, espera (projetos não sendo trabalhados) e de verificação e avaliação de projetos aquelas que não agregam valor (TZORTZOPOULOS, 1999). A eliminação de atividades que não agregam valor (desperdícios ou perdas) pode ser uma forma de melhorar o desempenho do processo de projeto, através da redução do seu lead time e também da concentração do esforço da equipe de projeto nas atividades que efetivamente agregam valor (HUOVILA et al., 1997).

O processo de projeto é um dos fluxos que fazem parte do fluxo de valor de um empreendimento de construção. Baggaley e Partner (2003) definem fluxo de valor como todos os passos realizados para criar valor para o cliente, desde a venda e desenvolvimento do produto até a assistência técnica após a entrega. Segundo Rother e Shook (1999), este fluxo abrange todas as ações que adicionam ou não valor ao produto, incluindo o fluxo da produção, a partir das matérias-primas até as mãos do cliente, e o fluxo do projeto do produto, da concepção até o lançamento.

Ao se aplicar o princípio de implementar o fluxo contínuo, cada processo dentro de um fluxo de valor deve produzir apenas o que é exigido pelo processo seguinte ou cliente final sem geração de estoque (WOMACK; JONES, 1996). Esse sistema de produção precisa ser flexível o bastante para mudar (velocidade e tipo de produto) de acordo com a demanda dos clientes (ROTHER; SHOOK, 1999). A redução do tamanho do lote contribui para reduzir o lead time de projeto, ou seja o tempo necessário para uma solução ou decisão de projeto atravesse todas as etapas do processo, incluindo as diferentes especialidades envolvidas, tais como, no caso da indústria da construção, projeto arquitetônico, estrutural, sistemas elétricos, sistemas hidros-sanitários, entre outros. Entretanto, a divisão do projeto em pequenos lotes tende a ser viável somente na etapa de projeto detalhado durante a fase de concepção do projeto de um edifício, por exemplo, é necessário considerar o projeto como um todo na tomada de decisões (TRESCASTRO, 2005).

O fluxo de projeto apresenta algumas peculiaridades em relação a outros fluxos: iteratividade entre atividades, pouca repetitividade, definição progressiva de meios e metas (BALLARD, 2002; REINERTSEN, 1997). Além disto, ao se aplicar o conceito de fluxo contínuo, não existe um cliente puxando uma peça, que é uma situação típica da manufatura, sendo necessário conhecer bem os processos posteriores e anteriores, de forma que o serviço seja executado e seu resultado esteja disponível no momento correto, nem antes, nem depois (REIS, 2004).

\section{Mapeamento do fluxo de valor}

Rother e Harris (2002) propõem como primeiro passo na implementação do fluxo contínuo o Mapeamento do Fluxo de Valor, incluindo os fluxos de materiais e informações, do produto ou família de produtos escolhida como foco de 
melhoria. O principal objetivo do mapa do fluxo de valor é identificar a ocorrência de desperdícios e tentar eliminá-los por meio de um novo projeto do sistema de produção, ou seja, define-se um estado futuro do sistema, no qual se busca implementar o fluxo contínuo (ROTHER; SHOOK, 1999).

No Mapa do Fluxo de Valor são representados os principais processos necessários para atender aos clientes, desde o pedido até a entrega (LIB, 2003). Este mapa representa uma descrição instantânea de um sistema de produção (por exemplo, uma fábrica), ilustrando como estão os estoques, a demanda, os tempos de ciclo, tempo takt, entre outras variáveis. Assim, deve ser redesenhado em diferentes momentos, a fim de revelar novas oportunidades de melhoria. É uma ferramenta predominantemente gráfica, que permite visualizar e entender processos, a partir da síntese de um conjunto de informações consideradas essenciais para identificar desperdícios (ROTHER; HARRIS, 2002).

O MFV foi inicialmente proposto para modelar sistemas de produção em uma fábrica (ROTHER; SHOOK, 1999), sendo depois estendido para a modelagem da cadeia de suprimentos (WOMACK; JONES, 1996). Também existem publicações sobre a aplicação desta ferramenta em processos administrativos (PICCHI, 2002; TAPPING; SHUKER, 2003; REIS, 2004).

Segundo Shook (2013), o MFV para os ambientes administrativos, tanto no estado atual quanto no estado futuro, deve ser feito de forma similar ao que é realizado na produção. Baseado na proposta para de Rother e Shook (1999) para a manufatura, Picchi (2002) apresenta diretrizes para adaptação do MFV aos ambientes administrativos:

(a) o fluxo de valor para administração é um só, o das informações e, em geral, este é desenhado da esquerda para a direita;

(b) cada atividade é representada por um bloco, devendo ser separadas as atividades feitas por diferentes pessoas, ou em momentos diferentes;

(c) os blocos devem conter as seguintes informações: nome da atividade, número de pessoas necessárias, descrição breve de como esta é realizada e dos materiais e ferramentas utilizados, o tempo de realização de atividade (TRA), e o tempo de permanência (TP) em cada posto; e

(d) as conexões entre atividades, as entradas e saídas, devem ser registradas, especificando o tipo de material ou informação que sai e os loops (idas e vindas).
Reis (2004) define o Tempo de Permanência (TP) em uma atividade como o tempo que a informação leva, a partir da saída da atividade anterior, até a saída da atividade em questão, e é indicado no MFV no bloco que a representa e na escala de tempo. O TP inclui o tempo em que a informação fica parada, esperando em filas ou sendo transportada, sem agregar nenhum valor. A soma de todos os tempos de permanência corresponde ao lead time do processo, que no MFV é indicado ao final da escala de tempo. Segundo a mesma autora, o Tempo de Realização da Atividade (TRA) é o tempo dos elementos de trabalho que efetivamente transformam uma unidade dentro do processo (ou seja, agregam valor), sendo, portanto menor ou igual ao TP, já este último inclui o TRA.

\section{Método de pesquisa}

A estratégia de pesquisa adotada foi a pesquisaação, que é definida por Thiollent (2005) como um tipo específico de pesquisa com base empírica que é concebida e realizada por meio de uma ação em que os pesquisadores e algumas pessoas participantes da situação ou do problema estão envolvidos de modo cooperativo. A realização da pesquisa-ação é justificada pela necessidade de implementar mudanças na empresa.

Foram realizados dois estudos empíricos em uma empresa de grande porte, especializada na produção de estruturas de concreto armado e protendido. Esta empresa possuía duas fábricas para produção das peças e atuava, principalmente, no Estado de São Paulo e, ocasionalmente, em outros estados do Brasil. O objeto de análise da pesquisa foi o processo de projeto das estruturas pré-fabricadas, sendo realizados estudos em dois empreendimentos (A e B), descritos brevemente a seguir:

(a) obra A: este estudo teve a duração de sete meses. Foi realizado um diagnóstico de todo o processo de desenvolvimento de um empreendimento, desde a consulta direta de preço do cliente à empresa até a entrega da obra. Apesar da análise ter sido bastante ampla, o foco deste diagnóstico foi o processo do projeto. A partir deste diagnóstico foi planejada a intervenção na obra B; e

(b) obra B: este estudo teve a duração de cinco meses. Foi proposta uma reestruturação do processo de projeto, na qual se buscou a redução do tamanho do lote dos projetos. Foram então introduzidas mudanças neste processo, o que possibilitou reflexões sobre a forma de gerenciar o desenvolvimento de produto na empresa. 
No Quadro 1 está apresentado um resumo com as principais características das obras, além de informações acerca dos seus processos de projeto.

$\mathrm{Na}$ obra A o projeto estrutural foi realizado por projetistas externos à empresa, enquanto na obra $\mathrm{B}$ a maior parte do projeto foi executada por uma equipe interna da empresa. A empresa decidiu pela formação da equipe interna de projeto para a Obra $\mathrm{B}$, com capacidade para realizar projetos de GE e DI. Houve uma reestruturação da equipe de projeto que já existia, sendo que dois profissionais anteriormente encarregados somente da verificação de projeto, passaram também a projetar.

Em ambas as obras a verificação dos projetos foi efetuada por equipes internas da empresa. A obra A consistia na ampliação de uma edificação industrial já existente, que havia sido executada por uma outra empresa. A obra B era a construção de um centro de distribuição com mezanino.

$\mathrm{Na}$ fase de diagnóstico, foram realizadas reuniões semanais conduzidas pela pesquisadora ${ }^{1}$, com o intuito de entender o processo, com os seguintes intervenientes: diretor técnico, projetistas internos e externos e coordenador de projeto. Foram elaborados dois mapas de fluxo de valor simplificados, um atual e outro futuro, com os dados obtidos nas reuniões. Após essa etapa inicial, foi elaborado um mapa detalhado do processo de projeto, a partir do acompanhamento de um empreendimento real (obra A). Por meio deste mapeamento, buscou-se conhecer em maior profundidade a natureza do processo de projeto de estruturas pré-fabricadas, já que a literatura é bastante escassa sobre o tema. Nessa etapa foi realizada uma análise detalhada de todos os subprocessos envolvidos, desde a consulta de preço feita pelo cliente até a verificação dos projetos de peças individuais, antes da entrega dos mesmos na fábrica. A elaboração dos mapas foi realizada pela pesquisadora, a partir de discussões realizadas com a equipe de projetistas.

Os dados para elaboração do mapa detalhado foram obtidos por meio de documentos internos da empresa, de reuniões com os profissionais envolvidos, e-mails trocados entre coordenador de projeto, cliente e projetistas, entrevistas abertas e participação da pesquisadora em reuniões de coordenação de projeto. Foram também coletados dados relativos às durações das atividades de projeto dos projetistas externos, que registraram todos os tempos gastos no projeto da obra A. Para esses registros usou-se uma planilha, contendo nome da peça e horas de projeto para forma e armação, elaborada pela pesquisadora.

\section{Quadro 1 - Caracterização das obras}

\begin{tabular}{|c|c|c|}
\hline Características & Obra A & Obra B \\
\hline Localização & Mogi das Cruzes/SP & Barueri/SP \\
\hline Descrição da obra & $\begin{array}{l}\text { Ampliação de edifício industrial } \\
\text { composto pelos seguintes tipos peças: } \\
\text { pilares, vigas, painéis de fechamento, } \\
\text { telhas e rufos de concreto. }\end{array}$ & $\begin{array}{l}\text { Construção da estrutura de um } \\
\text { centro de distribuição composto } \\
\text { pelos seguintes tipos peças: pilares, } \\
\text { vigas, lajes, telhas e escada. }\end{array}$ \\
\hline $\begin{array}{l}\text { Descrição do escopo do } \\
\text { contrato }\end{array}$ & $\begin{array}{l}\text { Projeto, fabricação e montagem das } \\
\text { peças estruturais. }\end{array}$ & $\begin{array}{l}\text { Projeto, fabricação e montagem das } \\
\text { peças estruturais. }\end{array}$ \\
\hline Área da obra $\left(\mathrm{m}^{2}\right)$ & $2.842,78$ & $89.846,86$ \\
\hline Volume da obra $\left(\mathrm{m}^{3}\right)$ & 365,86 & $7.759,8$ \\
\hline $\mathbf{N}^{\circ}$ de peças & 223 & 6.569 \\
\hline $\begin{array}{l}\text { Prazo da obra } \\
\text { (montagem) }\end{array}$ & 22 dias & 225 dias \\
\hline Prazo de projeto & 63 dias & 193 dias \\
\hline $\begin{array}{l}\text { Papel da equipe } \\
\text { interna de projeto }\end{array}$ & Verificação dos projetos. & $\begin{array}{l}\text { Projetos de Geometria Espacial da } \\
\text { Obra }(\mathrm{GE})^{1} \text {, de Detalhamento } \\
\text { Individual das Peças (DI), além da } \\
\text { verificação. }\end{array}$ \\
\hline
\end{tabular}

\footnotetext{
${ }^{1} \mathrm{O}$ projeto GE, também chamado de projeto geral, apresenta a distribuição de todas as peças da obra, com suas respectivas denominações.

${ }^{2}$ Primeira autora deste trabalho.
} 
Ao final da fase de diagnóstico foi feita uma avaliação do processo de projeto em reunião na empresa, conduzida pela pesquisadora, da qual participaram dois diretores, coordenador de projeto, projetistas internos da empresa, engenheira de planejamento e coordenador de obras. Nesta reunião, decidiu-se estender a implementação do fluxo continuo, que vinha sendo utilizado na montagem de peças pré-moldadas, ao processo de projeto. Além disso, decidiu-se pela realização do segundo estudo, no qual foi realizada uma intervenção no processo de projeto.

Para o segundo estudo, foi formada a equipe de projeto interna para elaboração do projeto da obra B. Nesse estudo a coordenadora de projeto da empresa foi a responsável pela implementação das melhorias, sendo o papel da pesquisadora o de facilitadora do processo. Duas vezes por mês aconteciam reuniões entre a coordenadora de projeto e a pesquisadora para acompanhamento da implementação, nas quais se discutia a a implementação das mudanças, particularmente a redução do tamanho do lote, e os problemas ocorridos no período.

Nesta fase, foram usadas outras fontes de evidência:

(a) participação em reuniões de coordenação de projeto;

(b) reuniões com o diretor técnico e os profissionais de projeto internos e externos; e

(c) entrevistas com três projetistas e a coordenadora de projeto.
Devido a limitações de tempo para a realização do segundo estudo, não foi possível avaliar o impacto das melhorias nos processos de fabricação em montagem.

\section{Resultados}

\section{Mapas de Fluxo de Valor atual e futuro}

Nas Figuras 1 e 2 está apresentado o Mapa de Fluxo de Valor detalhado das atividades de projeto. Para facilitar a visualização do Mapa, este foi dividido em duas partes (a e b). As caixas de processo nestes mapas estão divididas em quatro partes:

(a) o nome do processo;

(b) o setor ou pessoa responsável pela realização do processo;

(c) a descrição do processo; e

(d) as datas de início (I) e fim (F) dos processos.

Sob as caixas são apresentados o TRA (Tempo de Realização da Atividade) e o TP (Tempo de Permanência) dos processos. Para o cálculo do TP usou-se a diferença entre as datas de início e de fim, considerando apenas os dias úteis.

Considerou-se como inicio do processo de projeto a confirmação de compra pelo cliente. Essa confirmação não é feita por meio de assinatura do contrato, mas através de um documento enviado via e-mail. A partir dessa confirmação, a empresa pode dar seguimento ao processo de desenvolvimento do empreendimento.

Figura 1 - Mapa do Fluxo de Valor do processo de projeto - Obra A (parte a)
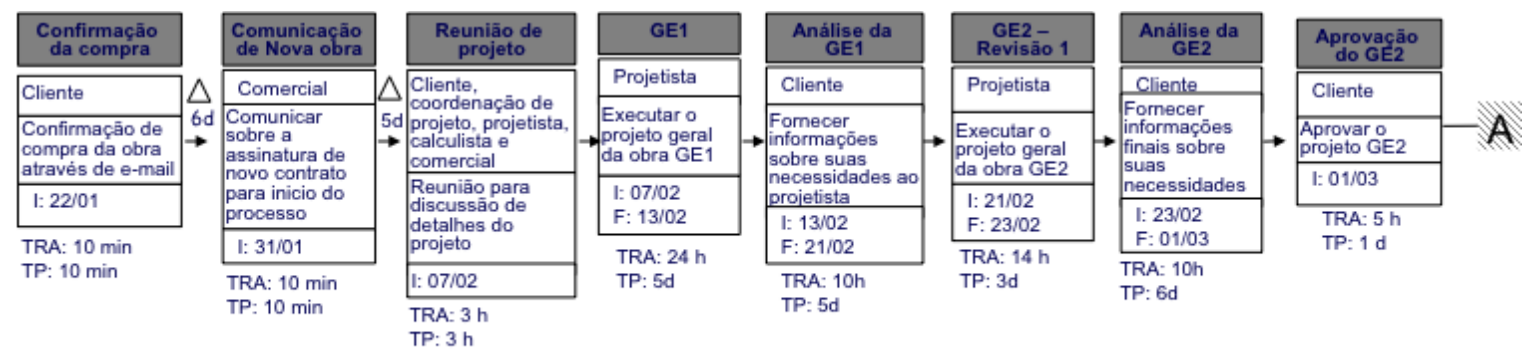

Nota: Legenda:
I: data de início da atividade;
F: data de fim da atividade;
TP: tempo de permanência; e
TRA: tempo de realização da atividade.

166 Bulhões, I. R.; Picchi, F. A. 
Figura 2 - Mapa do Fluxo de Valor do processo de projeto - Obra A (parte b)

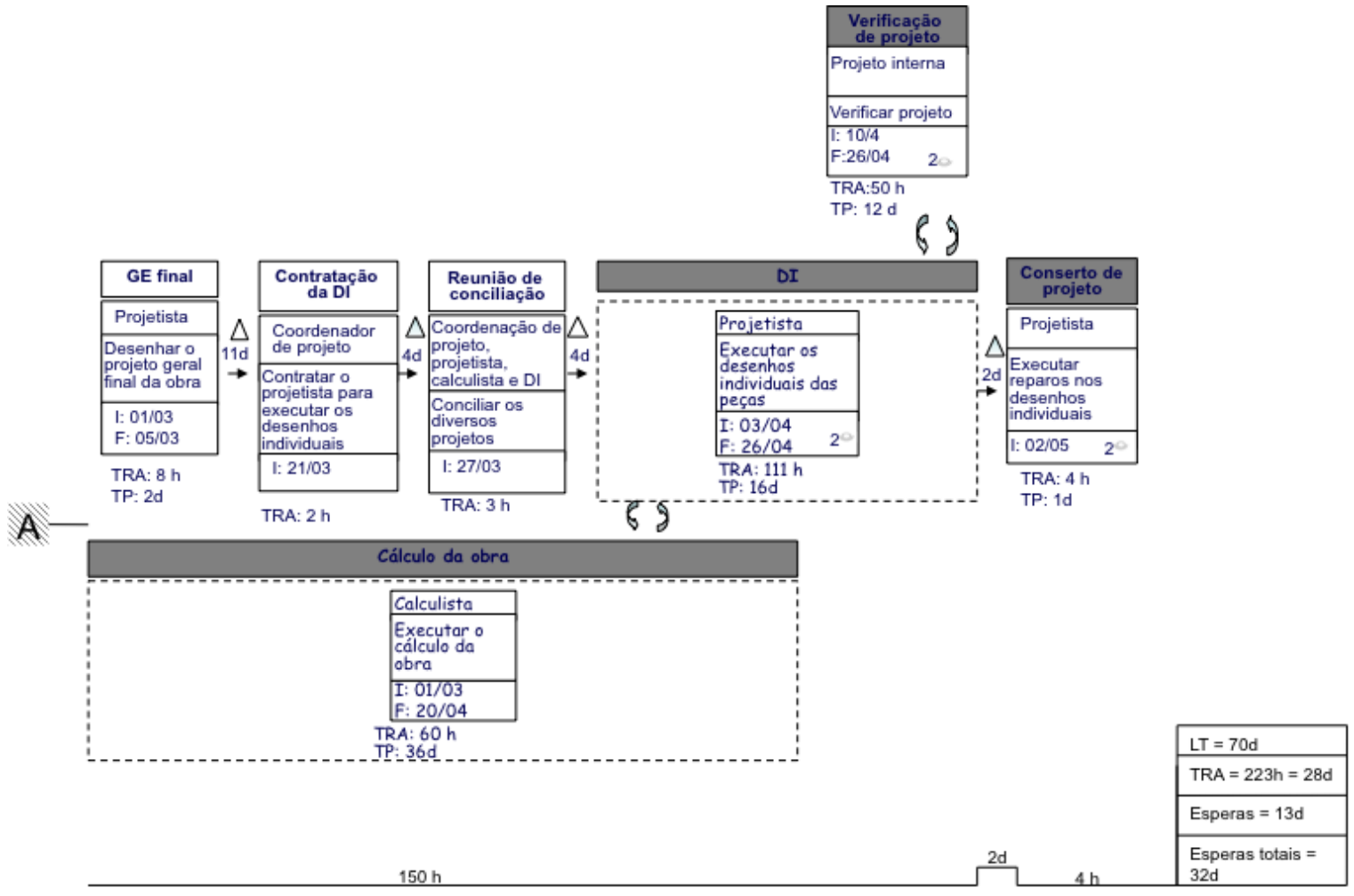

Nota: Legenda:
I: data de início da atividade;
F: data de fim da atividade;
TP: tempo de permanência; e
TRA: tempo de realização da atividade.

Na comunicação de nova obra, o setor comercial informa aos setores de planejamento de fábrica e de projeto que a obra foi contratada (Figura 1). No caso da obra A, existiu uma espera de 6 dias entre a confirmação de venda e a comunicação de nova obra. O processo de projeto foi iniciado com a reunião de projeto, que deve ser agendada o mais rápido possível a partir da comunicação de nova obra. Entretanto, nesse caso aconteceu apenas 5 dias após a comunicação da nova obra. Nessa reunião participaram o cliente, o coordenador de projeto, o projetista de GE (geometria espacial da obra), o calculista e o comercial. A partir dessa reunião, iniciaram-se o projeto de levantamento de carga e o ciclo da elaboração da GE (Figura 1).

O ciclo de elaboração da GE compreende as atividades necessárias para executar o projeto, apresentá-lo ao cliente, que fornece (ou não) mais informações sobre suas necessidades, até que seja aprovada a versão final do mesmo. Nesse ciclo não existiu comunicação direta entre projetista e cliente, sendo que coordenador de projeto teve o papel de intermediar essa comunicação. Durante a elaboração do projeto do GE, toda a comunicação entre coordenador de projeto, projetista e cliente foi realizada por e-mail. Esse processo foi planejado para ocorrer em 10 dias no cronograma, mas teve a duração de 17 dias, considerando apenas os dias úteis (Figura 1).

Após a aprovação do GE2 pelo cliente, pode ser iniciado o cálculo estrutural da obra, ainda na fase de elaboração da GE (Figura 2). Este cálculo é concluído na fase de projeto DI. Normalmente, após a elaboração da GE pode iniciar a fase de projeto das peças individuais (DI). É importante comentar que geralmente é contratado um único escritório de projeto, que realiza as atividades de projeto de GE, cálculo e projeto de DI. Neste caso específico excepcionalmente contrataram-se três profissionais diferentes para realizar essas atividades, sendo que isso gerou a necessidade de uma nova atividade, a reunião de conciliação, para evitar problemas de incompatibilidade de projetos, antes de iniciar os projetos de DI. Contudo, a contratação do projetista de DI demorou 11 dias e a reunião de conciliação demorou mais 4 dias para ocorrer e o projetista de DI demorou mais 4 dias 
para iniciar o projeto, gerando uma espera de 19 dias (parados) para início do projeto de DI.

À medida que os lotes de projeto de DI vão sendo concluídos, estes são verificados pela equipe interna da empresa para que se possa iniciar a fabricação das peças (Figura 2). Salienta-se que a simultaneidade que ocorre entre esses quatro processos do empreendimento (projeto, verificação, fabricação e montagem) dificulta a gestão desse tipo de obra, uma vez que problemas em qualquer um desses processos afetam os processos posteriores. $\mathrm{Na}$ obra $\mathrm{A}$, a grande divisão que ocorreu na equipe de projeto possivelmente foi a causa principal de um erro de projeto, relativo à cota de um pilar. Quando descoberto este erro, algumas peças já estavam montadas em obra e outras fabricadas, gerando grande retrabalho no projeto, montagem e fabricação.

Para a elaboração do mapa foram feitas as seguintes considerações:

(a) para o cálculo da TRA foi necessário definir o fluxo principal de valor, em função da existência de atividades em paralelo. Para isso consideraramse as seguintes opções:

- o fluxo formado pelas atividades de cálculo, projeto de DI e verificação de projeto; e

- o fluxo formado pelas atividades de projeto de GE final, contratação de projeto de DI, reunião de conciliação, projeto de DI e verificação de projeto. Considerou-se como fluxo principal a opção 1 porque tinha uma maior TRA (223h), seguindo a recomendação de Reis (2004). Nas Figuras 1 e 2 os processos do fluxo principal estão marcados em cinza.

(b) para as atividades de cálculo, aprovação da GE, projeto de DI e verificação, que ocorrem paralelamente, novamente se considerou o maior TRA. Como as atividades não eram completamente paralelas fez-se uma distribuição da média do TRA ao longo do período de elaboração destas atividades (Figura 3), considerando-se que o trabalho ocorreu de forma uniforme $^{3}$ ou seja, dividiu-se o TRA de cada atividade pela quantidade de dias trabalhos e usouse o maior valor; e

(c) ao final, comparou-se o TRA total (soma dos TRA's de todos os processos) com o lead time do processo (soma de todos os TP's e esperas).

Na Figura 2 é apresentada a diferença entre o lead time do projeto (70 dias) e o tempo de realização da atividade (26 dias) de 44 dias, sendo que o tempo de espera total foi de 32 dias, e durante o período de 13 dias o sistema ficou totalmente parado. Isto significa que ao longo do fluxo de valor do projeto, cerca de $70 \%$ do tempo não agregava valor.

Figura 3 - Cálculo do tempo de realização das atividades

\begin{tabular}{|c|c|c|c|c|c|c|c|c|c|c|c|c|c|c|c|c|c|c|c|c|c|c|c|}
\hline \multicolumn{2}{|c|}{ Processos } & \multicolumn{22}{|c|}{ Datas } \\
\hline Calculo & TRA médio & 1,7 & 1,7 & 1,7 & 1,7 & 1,7 & 1,7 & 1,7 & 1,7 & 1,7 & 1,7 & 1,7 & 1,7 & 1,7 & 1,7 & 1,7 & 1,7 & 1,7 & 1,7 & 1,7 & 1,7 & 1,7 & 1,7 \\
\hline $\begin{array}{c}\text { Aprovação } \\
\text { de GE }\end{array}$ & Dias trab & 1 & & & & & & & & & & & & & & & & & - & 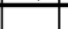 & 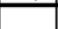 & & \\
\hline \multirow[b]{2}{*}{$\mathrm{DI}$} & \begin{tabular}{|l|} 
Dias trab \\
\end{tabular} & & & & & & & & & & & & & & & & & & & & & & \\
\hline & TRA médio & & & & & & & & & & & & & & & & & & & & & & \\
\hline \multirow[b]{2}{*}{ Verificação } & Dias trab & & & & & & & & & & & & & & & & & & & & & & \\
\hline & TRA médio & & & & & & & & & & & & & & & & & & & & & & \\
\hline \multicolumn{2}{|c|}{\begin{tabular}{c|l} 
& Dias trab \\
\cline { 2 - 3 } Reparo & TRA médio \\
TRA máximo
\end{tabular}} & 5,0 & 1,7 & 1,7 & 1,7 & 1,7 & 1,7 & 1,7 & 1,7 & 1,7 & 1,7 & 1,7 & 1,7 & 1,7 & 1,7 & 1,7 & 1,7 & 1,7 & 1,7 & 1,7 & 1,7 & 1,7 & 1,7 \\
\hline
\end{tabular}

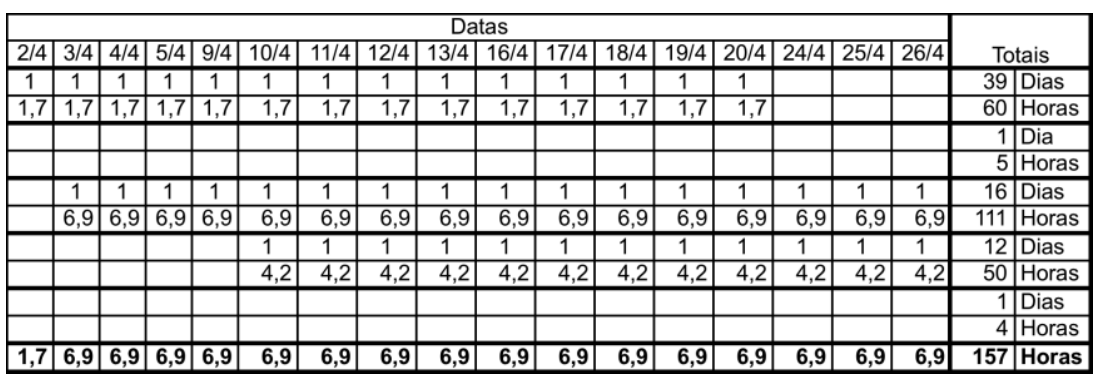

\footnotetext{
${ }^{3}$ Apesar do trabalho efetivamente não ocorrer de forma uniforme, essa foi uma limitação dos dados obtidos, já que os profissionais envolvidos na coleta de dados registraram apenas o total de horas trabalhadas.
} 
Em relação à eficácia em relação a prazo, a duração planejada do processo de projeto e acordada em cronograma com o cliente, era de 63 dias e, devido aos problemas iniciais, ocorreu em 70 dias. Em termos absolutos ocorreu um atraso de 7 dias na conclusão do projeto. Porém, o maior impacto desse atraso foi na fabricação das peças, pois os projetos individuais iniciaram 12 dias após o planejado. Esse atraso afetou todo o plano de fabricação e de montagem das peças resultando em muitas mudanças na programação das fábricas e na seqüência de montagem.

A partir do diagnóstico, foi elaborado um Mapa de Fluxo de Valor futuro detalhado, apresentado na Figura 4. Nessa proposta, o processo de projeto inicia por uma reunião para discussão sobre o escopo do projeto (reunião de projeto), da qual participam o representante do cliente, projetistas e o coordenador de projeto. Diferentemente da reunião que ocorria no processo atual da empresa, no mapa futuro o coordenador de projetos deve apresentar alternativas de projeto ao cliente, tais como, por exemplo, a posição da escada, visando a evitar mudanças posteriores na elaboração do projeto de GE. Assim, a primeira reunião de projeto teria um enfoque pró-ativo na captação de requisitos e na tomada de decisões sobre o projeto como um todo.

Após a reunião, o projetista de GE inicia o trabalho e, após a conclusão da primeira versão deste projeto, existe uma nova reunião, denominada reunião de aprovação, entre os mesmos intervenientes da reunião de projeto, para apresentação da primeira versão do projeto de GE para o cliente. Se esta versão inicial do projeto GE não for aprovada, os próprios projetistas devem captar novas necessidades do cliente para que sejam incorporadas na nova versão do GE. Outra modificação no processo de projeto é a participação mais intensa do coordenador de projeto na captação de requisitos e na elaboração de alternativas de projeto. Uma vez aprovada a primeira versão do projeto de GE, o projetista elabora a versão final deste.

Uma das inovações mais importantes propostas foi a introdução da reunião de definição dos fluxos do empreendimento, envolvendo o coordenador de projeto, projetistas, representante do cliente, engenheiro de obra e engenheiro de planejamento da fábrica. O principal papel desta reunião é tomar decisões sobre o processo de projeto em pequenos lotes, no qual os lotes de montagem puxam as atividades de cálculo de peças individuais, projeto de DI e verificação. Contudo, o lote de projeto não é necessariamente igual ao de montagem, mas o lote de projeto deve atender ao seqüenciamento estabelecido nos planos de fabricação das peças de montagem da estrutura na obra, atendendo aos prazos de entrega demandados pelos processos posteriores.

Figura 4 - Mapa de Fluxo de Valor futuro do processo de projeto

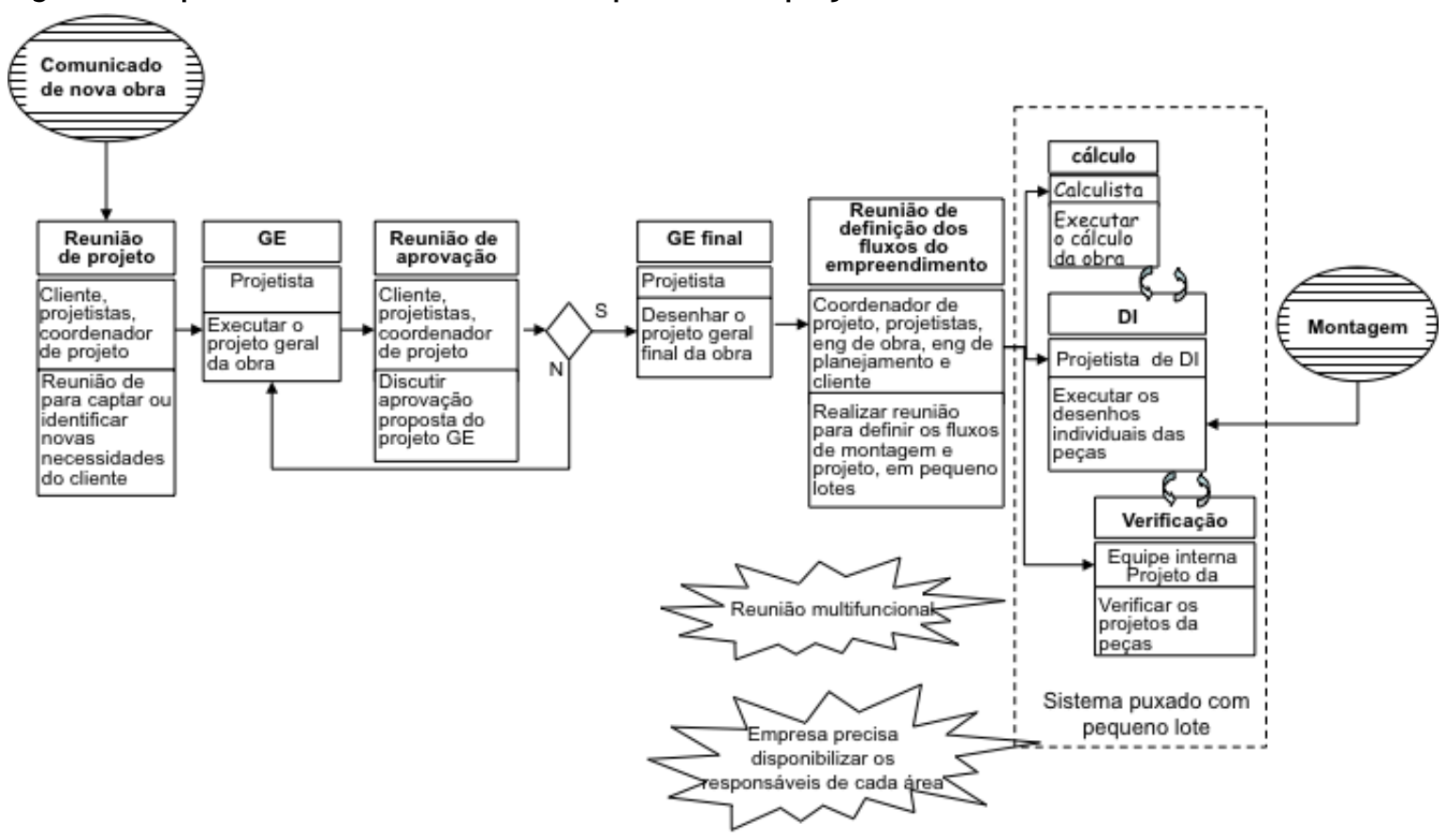


Assim, na proposta de mapa futuro (Figura 4), esta reunião visa a criar condições para um planejamento de forma integrada do sistema projeto-fabricação-montagem, com o objetivo de sincronizar os lotes de projeto e produção em fábrica com a seqüência de lotes de montagem, os quais devem puxar os processos anteriores. Além disso, a participação do representante do cliente visa a considerar os requisitos do mesmo na seqüência de montagem, evitando mudanças posteriores na execução da obra e conseqüente mudança em todo o sistema. Nessa reunião as decisões devem ser formalizadas em ata assinada por todos os participantes.

Após essa reunião, inicia o trabalho dos projetistas de cálculo e de DI, sendo que a atividade de verificação inicia-se a partir do primeiro lote de projeto DI pronto. Pensou-se na possibilidade de criação de uma célula de trabalho envolvendo estes três processos, mas foi considerado inviável pois a maioria dos empreendimentos tem projetos executados por profissionais diferentes e em diferentes locais.

Levando-se em conta a primeira análise do processo de projeto, foram também sugeridas as seguintes ações adicionais para melhoria do fluxo de projeto:

(a) aliminação da atividade de controle de entrega dos projetos individuais de peças: normalmente, $o$ projetista de DI envia para empresa os projetos de peças, um a um, por meio de uma plataforma de colaboração. Existe um funcionário da empresa que verifica diariamente os projetos enviados, cabendo a este imprimi-los e entregá-los à equipe de verificação. Ao se definir a entrega do projeto em pequenos lotes, os projetistas passariam a enviar lotes de projeto, ao invés de projetos individuais, numa freqüência pré-estabelecida (por exemplo, uma ou duas vezes por semana). Este procedimento elimina esta atividade de controle, que não agrega valor;

(b) eliminação de alguns tempos de espera, tais como aqueles indicados nas Figuras 1 e 2, em função de não existir justificativas para ocorrer essas esperas; e

(c) o sub-processo de verificação deveria ter um monitoramento sistemático dos erros de projeto de forma a retro-alimentar os projetistas e evitar a reincidência de problemas. Desta forma, no longo prazo, esta atividade, que não agrega valor, poderia ser eliminada.

\section{Implementação do fluxo contínuo no projeto: obra B}

Após o diagnóstico, iniciou-se a implementação das mudanças planejadas no processo de projeto na obra B. No cronograma acordado com o cliente, foram definidos dois prazos de entrega, conforme Figura 5. A obra era constituída de um galpão (na horizontal, eixos de 4 ao 40 e na vertical, eixos de A ao $\mathrm{H}$ ) que contém um mezaninos na parte inferior (na horizontal, eixos de 4 ao 40 e na vertical, eixos de $\mathrm{A}$ ao $\mathrm{A} 1$ ) e de um mezanino à direita (na horizontal, eixos de 1 ao 4 e na vertical, eixos de $\mathrm{F}$ ao $\mathrm{C}$ ), conforme pode ser observado na Figura 5. A prioridade de entrega era o mezanino localizado à direita, pois a maioria das obras civis era concentrada nessa região, onde seria construído o escritório do centro de distribuição. Além disto, o mezanino tende a ser a área na qual o projeto é mais complexo, pois envolve um maior número de peças e, além do mais, existe grande interferência do cliente.

Figura 5 - Obra dividida conforme prazo de entrega

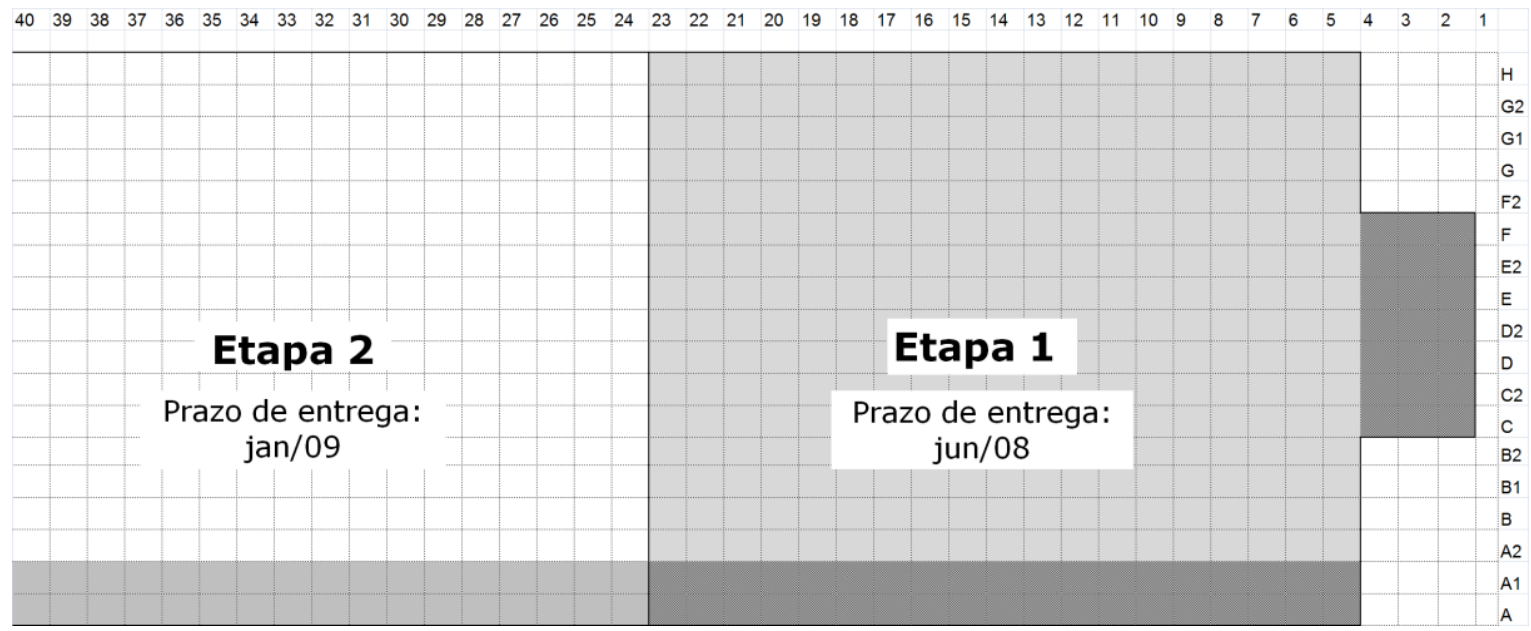

170 Bulhões, I. R.; Picchi, F. A. 
Uma das características desse projeto foi a necessidade de sobrepor muitas das atividades de projeto assumidas como sequenciais no MFV futuro, apresentado na Figura 4. O projeto de GE iniciou antes mesmo da confirmação de nova obra, devido ao fato de que era um contrato de elevado valor e algumas decisões deste projeto poderiam contribuir para as negociações com o cliente. A reunião inicial de projeto ocorreu na sede do cliente, contando com a presença do representante do cliente, coordenador de projeto, um projetista interno e o profissional responsável pelo contato com o cliente. Contudo, havia ainda várias indefinições do projeto, principalmente relacionadas ao mezanino e à localização da escada.

A data de conclusão prevista para o projeto de GE era 6/2/2008. Entretanto, este projeto atrasou, sendo concluído somente em 18/03/2008. A principal causa deste atraso foi a demora na tomada de decisão por parte do cliente, apesar do mesmo ter conhecimento das datas limites para as diferentes etapas do projeto

O início do projeto de DI também teve que ser antecipado para 23/12/2007, antes da conclusão do projeto de GE, em função do grande número de telhas (3.823 peças) a serem fabricadas (inicio planejado para 03/01/2008), as quais necessitavam de projeto. De fato, havia se decidido na reunião de 4/12/2007, que o projeto e fabricação das telhas não seguiriam a sequiência dos lotes de projeto definidos para as demais peças, pois as mesmas necessitavam de um maior tempo para a fabricação, devido a limitações de capacidade da fábrica.

Em função do atraso do projeto GE, os projetos de DI das demais peças foram sendo elaborados em paralelo, para não atrasar o prazo do projeto. Os projetistas internos fizeram o pré-projeto de algumas peças, cuja conclusão dependia de algumas definições do cliente. Isso ocasionou muitos retrabalhos e a elaboração de projetos adicionais de peças.

Em 4/12/2007, muito antes do final do projeto de GE, foi realizada a reunião para a primeira definição dos lotes de projeto entre os projetistas internos, o calculista (esse externo), coordenador de projeto e pesquisadora. Ao fim da reunião, datas para cada lote de projeto foram decididas e acordadas com os projetistas. Porém, a confirmação destas datas dependia de algumas definições do cliente, referentes ao projeto de GE.

Na Figura 6 está apresentada a divisão final da obra em lotes de projeto de DI.

Inicialmente o plano previa nove lotes de projeto (Lp1 a Lp9). Porém no plano final, o número de lotes de projeto foi reduzido para cinco, sendo agrupados os lotes Lp1 a Lp4 e Lp7 e Lp8 (Figura 6). Com relação às datas, as entregas previstas dos lotes tiveram que ser adiadas, com exceção do Lp1, que foi re-planejado para ser concluído antes data prevista. De fato, a equipe de projeto havia adiantado os projetos de DI destes lotes em função de atrasos dos demais.

Inicialmente tinha sido previsto que a obra começasse pelo mezanino. porém, observa-se que o lote Lp2 de galpão tinha a data de entrega anterior ao lote Lp1 do mezanino em função, não apenas da montagem da obra, mas também da capacidade da fábrica. De fato, conforme sugestão apresentada a partir do MFV futuro, o lote de projeto deve atender aos planos de fabricação das peças e atender aos prazos de entrega demandados pelos processos posteriores. Em função da falta de definição de alguns elementos no mezanino, houve necessidade de reformular duas vezes o plano de lotes de projeto de DI.

Figura 6 - Divisão da obra final em lotes de projeto de DI

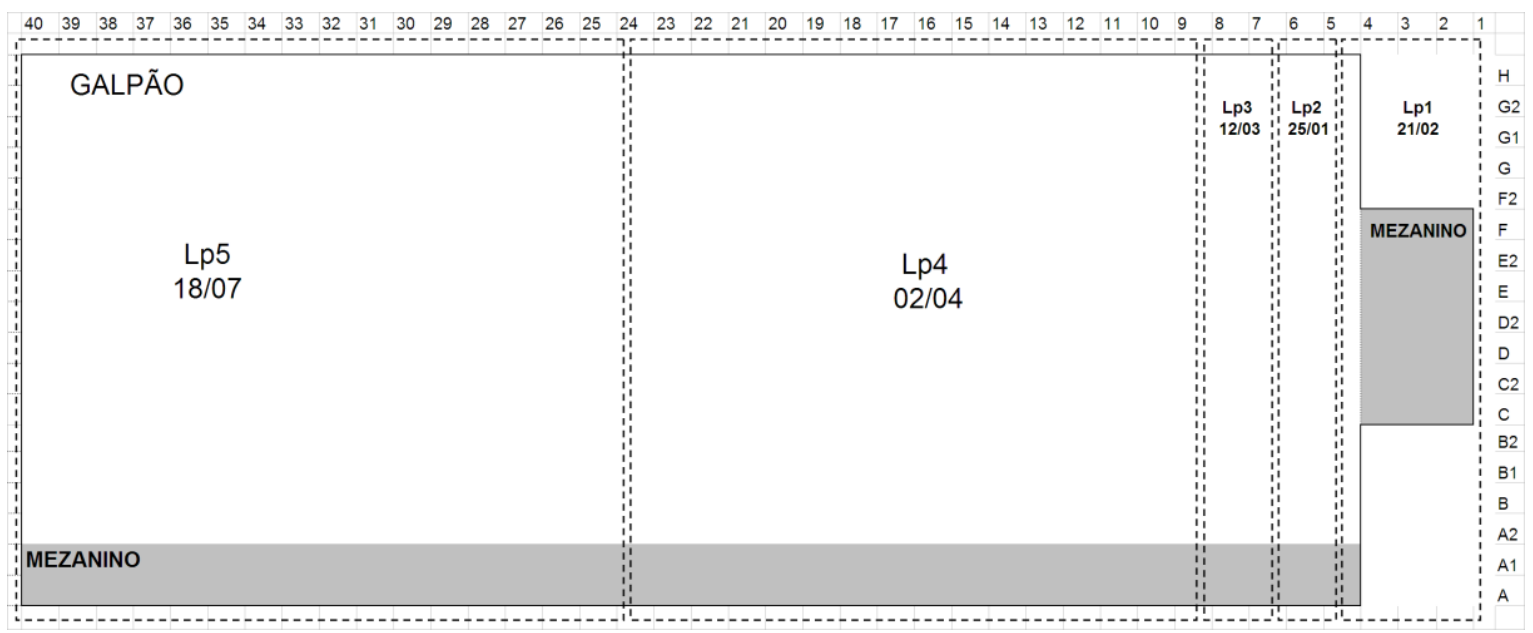


Em relação à implementação do processo de projeto definido no MFV futuro, foram observadas dificuldades de realizar as reuniões ao longo do mesmo, entre as quais podem ser salientadas as seguintes:

(a) dada a importância estratégica do empreendimento pela empresa, algumas atividades de projeto tiveram que ser antecipadas, conforme mencionado acima. Por esta razão as três reuniões previstas para a tomada de decisão (reunião de projeto, reunião de aprovação, e reunião de definição dos fluxos do empreendimento) não puderam ser realizadas no estágio de desenvolvimento do projeto adequado;

(b) constatou-se a necessidade de mudanças organizacionais, que criem disponibilidade de tempo para que os profissionais a serem envolvidos possam efetivamente participar destas reuniões; e

(c) houve dificuldade de obter o comprometimento de alguns profissionais da própria empresa (por exemplo, a participação de gerentes de obras em reuniões de projeto), e de projetistas internos, com as mudanças propostas. Neste sentido, constatou-se necessidade de investimentos em treinamento e em mudanças comportamentais.

Apesar dos problemas encontrados na implementação das mudanças propostas, algumas melhorias foram introduzidas com sucesso, podendo ser destacada a introdução de um planejamento de lotes de projeto de DI na empresa, a partir da demanda dos processos de fabricação e montagem. Além disto, foi desenvolvida pela própria coordenadora de projetos uma planilha que formaliza o planejamento e controle de projetos. Nesta planilha, constava o sentido de montagem, informações sobre versões de projeto, datas de entregas previstas, composição dos lotes de projeto de DI, causas de atraso e situação atual de cada lote (adiantou, no prazo, ou atrasou), entre outras informações.

\section{Análise dos resultados}

O mapeamento do fluxo de valor teve um papel importante no diagnóstico do processo de projeto de estruturas de concreto pré-fabricado e protendido, tendo sido eficaz em evidenciar as atividades que não agregam valor no processo. Da mesma forma, o MFV futuro contribuiu no sentido de explicitar a proposta de implementação de mudanças acordada entre a pesquisadora e os intervenientes da empresa.

No processo de implementação, observou-se que a obra estudada demandava um processo de projeto com grande simultaneidade entre atividades, o que não havia sido previsto no MFV proposto, cujos sub-processos eram de natureza predominantemente sequencial. No mapa (Figura 4), as 5 primeiras atividades foram planejadas para ocorrerem sequencialmente. Porém, isto não foi possível na obra $\mathrm{B}$, indicando a necessidade de estudar em maior profundidade a aplicação desta ferramenta em ambientes complexos, nos quais não é possível definir uma sequência rígida de atividades.

Essa questão foi levantada no decorrer de todo o estudo, nas discussões sobre o processo futuro com os representantes da empresa. Identificou-se que existem diferentes tipos de obras e que provavelmente não deve haver um modelo único do processo de projeto para todas elas. Foram feitas algumas reuniões nas quais se discutiu os critérios para classificar as obras segundo o seu grau de complexidade, levando-se em conta diversos fatores, entre os quais as características do empreendimento: prazo, tamanho da obra, e grau de padronização e repetitividade das peças. É importante também considerar as diferenças que existem no processo de projeto em função da importância estratégica do cliente e também da equipe gerencial envolvida nas negociações. Assim, poderiam ser adotados diferentes modelos de processo de projeto em função das características das obras e dos clientes. Em alguns casos, o processo pode ser mais padronizado e sequiencial, em outros existe necessidade de maior flexibilidade no processo, em função das suas características de simultaneidade e interatividade.

O estudo empírico indicou também que a redução o tamanho do lote é viável de ser implementado e pode trazer benefícios imediatos ao processo de projeto de estruturas pré-fabricadas. As entrevistas não estruturadas finais com a coordenadora de projetos e membros da equipe interna de projeto ofereceram evidências neste sentido.

Observou-se nos Mapas (tanto o atual quanto o futuro) um decoupling point ${ }^{4}$, localizado entre a elaboração de GE e o Desenho Individual, ou seja, o ponto no qual a produção de projetos deixa de ser empurrada e passa a ser puxada. Foi inclusive identificada a oportunidade para trabalhar com o conceito de célula de produção de projeto, envolvendo o calculista, projetista de DI e projetista de verificação, que poderia ser explorada no futuro pela empresa. Entretanto, este decoupling point pode tornar-se difícil de ser identificado à medida que algumas decisões do projeto de GE são postergadas e alguns projetos de DI necessitam ser antecipados em função de peças

\footnotetext{
${ }^{4}$ Pode ser traduzido como ponto de desacoplamento.
} 
com lead times de fabricação maiores, como foi o caso das telhas.

A utilização de equipes multifuncionais foi uma das melhorias mais importantes propostas no MFV futuro. Foram propostas diferentes equipes para os seguintes estágios do processo de projeto:

(a) na reunião inicial de projeto para a captação de requisitos e tomada de decisão sobre o projeto conceitual;

(b) na reunião de avaliação do projeto de GE com o cliente; $\mathrm{e}$

(c) na reunião de definição dos fluxos dos empreendimentos.

\section{Conclusões}

$\mathrm{O}$ artigo apresentou os resultados de uma proposta de implementação de fluxo contínuo em projeto, baseado, principalmente, na redução do tamanho do lote. Essa proposta foi baseada num diagnóstico elaborado com auxílio da ferramenta do Mapa do Fluxo de Valor, adaptado para esse contexto. Com relação ao uso MFV no diagnóstico do processo de projeto, concluiu-se que sua aplicação permitiu identificar diversos problemas, principalmente no que se refere a apontar as atividades que não agregam valor. Entretanto, foram encontradas dificuldade em adaptar esta ferramenta à natureza do processo de projeto, principalmente no caso de realização de atividades simultâneas, iterativas e cíclicas.

Com relação à implementação do fluxo contínuo em projeto propôs-se a utilização de equipes multifuncionais e a redução do tamanho do lote de projeto. Este lote não é exatamente o mesmo lote de montagem, devendo-se levar em conta para a definição do mesmo, a capacidade da fábrica e a sequência de montagem estabelecida. A utilização de lotes reduzidos de projeto, que leve em conta os outros sub-sistemas da empresa e que não seja definido arbitrariamente pelos projetistas, contribui para melhorar o sistema como um todo.

Apesar de não ter sido o foco do estudo a implementação da produção puxada, observou-se a possibilidade de uso desse conceito no contexto de projeto, principalmente pela identificação do decoupling point.

A utilização de equipes multifuncionais foi uma das melhorias mais importantes propostas no MFV futuro. Entretanto as dificuldades observadas na realização das reuniões indicam necessidade de mudanças organizacionais, que criem disponibilidade de tempo para que os profissionais a serem envolvidos possam efetivamente participar destas reuniões e necessidade de investimentos em treinamento, tanto no que se refere a conceitos e princípios de gestão da produção, como também nas tecnologias envolvidas na produção de estruturas de concreto pré-fabricadas.

Como sugestões de trabalhos futuros, pode-se destacar a necessidade de estudar o impacto da complexidade dos empreendimentos, decorrentes tanto das características do projeto como também dos agentes envolvidos, na modelagem do processo de projeto, particularmente no que se refere à explicitação de atividades que não agregam valor. Deve também receber a atenção a aplicação de alguns dos conceitos abordados nesta pesquisa (por exemplo, redução do tamanho do lote, fluxo contínuo) em outros tipos de projeto, com características diferentes daqueles estudados no presente trabalho.

\section{Referências}

AUSTIN, S.; BALDWIN, A.; NEWTON, A. Manipulating the Flow of Design Information to Improve the Programming of Building Design. Construction Management and Economics, v. 12, n. 5, p. 445-455, set 1994.

BAGGALEY, B. L.; PARTNER, S. Value Stream Management for Lean Companies. Journal of Cost Management, v. 17, n. 2. p. 23-27, mar./apr. 2003.

BALLARD, G. Managing Work Flow on Design Projects: a case study. Engineering, Construction and Architectural Management, Leicestershire, v. 9, n. 3, p. 284-291, 2002.

BALLARD, G.; HARPER, N.; ZABELLE, T. Learning to See Work Flow: an application of lean concepts to precast concrete fabrication.

Engineering, Construction and Architectural Management, v. 10, n. 1, p. 6-14, 2003.

BULHÕES, I. Diretrizes Para Implementação de Fluxo Contínuo na Construção Civil: uma abordagem baseada na Mentalidade Enxuta. Campinas, SP, 2009. 361 f. Tese (Doutor em Engenharia Civil) - Faculdade de Engenharia Civil, Arquitetura e Urbanismo, Universidade Estadual de Campinas, Campinas, SP, 2009.

DENTZ, J.; NAHMENS, I.; MULLENS, M. Applying Lean Production in Factory Homebuilding. Cityscape: A Journal of Policy Development and Research, v. 11, n. 1, 2009.

HUOVILA, P.; KOSKELA, L.; LAUTANALA, M. Fast or Concurrent: the art of getting construction improved. In: ALARCÓN, L. Lean Construction. Rotterdam, 1997. p. 143-160. 
KOSKELA, L. An Exploration Towards a Production Theory and Its Application to Construction. Espoo, Finlândia: VTT, 2000. (VTT Publications, 408).

KOSKELA, L. Application of the New Production Philosophy to Construction. Stanford: Stanford University, 1992. (Technical Report, 72).

KOSKELA, L.; BALLARD, G.; TANHUANPÄÄ, V. Towards Lean Design Management. In: LEAN CONSTRUCTION SEMINAR, 2., São Paulo, 1997. Proceedings... São Paulo, 1997.

KOSKELA, L.; HUOVILA, P. On Foundations of Concurrent Engineering. In: Concurrent Engineering in Construction. London: The Institution of Structural Engineers, 1997. p. 22-32.

LEAN INSTITUTE BRASIL. Léxico Lean: glossário ilustrado para praticantes do pensamento lean. Tradução de Lean Institute Brasil. São Paulo: Lean Institute Brasil, 2003.

LIKER, J. K. The Toyota Way: 14 management principles from the world's greatest manufacturer. New York: McGraw-Hill, 2004. 330 p.

PICCHI, F. A. Lean na Administração. In: LEAN SUMMIT 2002, Gramado, 2002. Apresentações... Gramado: Lean Institute Brasil, 2002.

REINERTSEN, D. G. Managing the Design Factory: a product developer's toolkit. New York, Free Press, 1997. 269 p.

REIS, T. dos. Aplicação da Mentalidade Enxuta no Fluxo de Negócios da Construção Civil a Partir do Mapeamento do Fluxo de Valor. Campinas, SP, 2004. 125 f. Dissertação (Mestrado em Engenharia Civil) - Faculdade de Engenharia Civil, Arquitetura e Urbanismo, Universidade Estadual de Campinas, Campinas, SP, 2004.

ROTHER, M.; HARRIS, R. Criando o Fluxo Contínuo: um guia de ação para gerentes, engenheiros e associados da produção. São Paulo: Lean Institute Brasil, 2002.

ROTHER, M.; SHOOK, J. Aprendendo a Enxergar. São Paulo: Lean Institute, 2002.

ROTHER, M.; SHOOK, J. Aprendendo a Enxergar: mapeando o fluxo de valor para agregar valor e eliminar o desperdício. São Paulo: Lean Institute Brasil, 1999.

SACKS, R.; AKINCI, B.; ERGEN, E. 3D Modeling and Real-Time Monitoring In Support of Lean Production of Engineered-To-Order Precast Concrete Buildings. In: INTERNATIONAL GROUP FOR LEAN CONSTRUCTION, Virginia, 2003. Proceedings... Virginia: Virginia Tech, 2003.
SANTOS, A. Application of Flow Principles in the Production Management of Construction Sites. Salford, 1999, Thesis (Ph.D.) - School of Construction and Property Management, The University of Salford, Salford, 1999.

SHOOK, J. Helpful Hints on Mapping off the Plant Floor in Support or Administrative Operations. Disponível em:

<http://www.lean.org/Library/Helpful_Hints_on_ Mapping_off_the_Plant_Floor.pdf $>$. Acesso em: 15 mar. 2013.

TAPPING, D.; SHUKER, T. Value Stream Management For the Lean Office: 8 steps to planning, mapping, and sustaining lean improvements in administrative areas. New York: Productivity Press, 2003. 171 p.

THIOLLENT, M. Metodologia da PesquisaAção. 14. ed. São Paulo: Cortez, 2005. 132 p.

TRESCASTRO, M. G. Diretrizes Para a Segmentação e Seqüenciamento das Atividades no Processo de Projeto em Ambientes Simultâneos na Construção Civil. Porto Alegre, 2005. 163 f. Dissertação (Mestrado em Engenharia Civil) - Escola de Engenharia, Universidade Federal do Rio Grande do Sul, Porto Alegre, 2005.

TZORTZOPOULOS, P. Contribuições Para o Desenvolvimento de Um Modelo do Processo de Projeto de Edificações em Empresas Construtoras Incorporadoras de Pequeno Porte. Porto Alegre, 1999. 163 f. Dissertação (Mestrado em Engenharia Civil) - Escola de Engenharia, Universidade Federal do Rio Grande do Sul, Porto Alegre, 1999.

WILLIAMS, T. Modelling Complex Projects. Chichester: John Wiley \& Sons, 2002.

WOMACK, J. P.; JONES D. T. A Mentalidade Enxuta nas empresas: elimine o desperdício e crie riqueza. Tradução de Ana Beatriz Rodrigues e Priscila Martins Celeste. 5. ed. Rio de Janeiro: campus, 1996.

YU, H. et al. Development of Lean Model For House Construction Using Value Stream Mapping. Journal of Construction Engineering and Management, v. 135, n. 8, p. 782-790, 2009.

\section{Agradecimentos}

Os autores gostariam de agradecer a FAPESB (Fundação de Amparo a Pesquisa do Estado da Bahia) pelo apoio financeiro.

174 Bulhões, I. R.; Picchi, F. A. 
lamara Rossi Bulhões

Departamento de Construção e Estrutura | Universidade Federal da Bahia | Rua Aristides Novis, 02, Federação | Salvador - BA- Brasil | CEP 44031-460 | Tel.: (71) 3283-9525 | E-mail: iamara@ufba.br

Flávio Augusto Picchi

Lean Institute Brasil | Universidade Estadual de Campinas | Rua Brás Cubas, 187, Aclimação | São Paulo - SP - Brasil | CEP $04105-063$ | Tel.: (11) 5571-0804 | E-mail: fpicchi@lean.org.br

Revista Ambiente Construído

Associação Nacional de Tecnologia do Ambiente Construído

Av. Osvaldo Aranha, $99-3^{\circ}$ andar, Centro

Porto Alegre - RS - Brasil

CEP $90035-190$

Telefone: +55 (51) 3308-4084

Fax: +55 (51) 3308-4054

www.seer.ufrgs.br/ambienteconstruido

E-mail: ambienteconstruido@ufrgs.br 